\title{
Photocatalytic Characterization of Fe- and Cu-Doped ZnO Nanorods Synthesized by Cohydrolysis
}

\author{
Young Rang Uhm, ${ }^{1}$ Byung Sun Han, ${ }^{2}$ Chang Kyu Rhee, ${ }^{3}$ and Sun Ju Choi ${ }^{1}$ \\ ${ }^{1}$ Radioisotope Research Division, Korea Atomic Energy Research Institute (KAERI), 989 Daedukdaero, \\ Daejeon 305-353, Republic of Korea \\ ${ }^{2}$ Miraenanotech, Cheongwon, Chungcheongbuk-do 363-911, Republic of Korea \\ ${ }^{3}$ Nuclear Materials Development Division, Korea Atomic Energy Research Institute (KAERI), Daejeon 305-353, Republic of Korea
}

Correspondence should be addressed to Young Rang Uhm; uyrang@kaeri.re.kr

Received 10 July 2013; Revised 25 September 2013; Accepted 26 September 2013

Academic Editor: Huogen Yu

Copyright (C) 2013 Young Rang Uhm et al. This is an open access article distributed under the Creative Commons Attribution License, which permits unrestricted use, distribution, and reproduction in any medium, provided the original work is properly cited.

\begin{abstract}
$\mathrm{Fe}$ - and $\mathrm{Cu}$-doped $\mathrm{ZnO}$ nanorods have been synthesized by a novel process employing a hydrolysis of metal powders. Zn, Fe, and $\mathrm{Cu}$ nanopowders were used as starting materials and incorporated into distilled water. The solution was refluxed at $60^{\circ} \mathrm{C}$ for $24 \mathrm{~h}$ to obtain the precipitates from the hydrolysis of $\mathrm{Zn}$ and dopants ( $\mathrm{Cu}$ and $\mathrm{Fe}$ ). The TEM results for $\mathrm{ZnO}$ with and without metal doping showed that the produced powders had a rod-like shape. The rod shape was attributable to the zinc oxide from the hydrolysis of $\mathrm{Zn}$. With an increasing doping content, the UV-vis spectra were shifted to a long wavelength and this result indicates that the band gap was changed by the metal doping. The values of phenol degrading $\mathrm{Fe}$ - and $\mathrm{Cu}$-doped $\mathrm{ZnO}$ by a solar simulator were measured to be 60 and $75 \%$, respectively.
\end{abstract}

\section{Introduction}

Zinc oxide $(\mathrm{ZnO})$ powders show important applications in catalyst, surface acoustic wave devices, cosmetic pigments, varistors, ultraviolet (UV) absorbers, optical materials, gas sensors, and as window material for displays and solar cell [1]. Microstructure and chemical properties of $\mathrm{ZnO}$ powders depend upon the synthesis method of this material. Different synthesis methods were used to fabricate $\mathrm{ZnO}$ particles with various sizes and morphologies. Accordingly, the synthesis of $\mathrm{ZnO}$ fine particles is of great importance for basic research. The size-dependent effects are correlated with the physical properties and structure of the system, for example, the size dependence of the electron-phonon coupling, the size dependence of surface luminescence of $\mathrm{ZnO}$ nanowires, the compressibility, and the transition pressure [2]. Metaldoped $\mathrm{ZnO}$ is generally investigated in the form of diluted magnetic semiconductor (DMS) materials and photocatalyst, because it shows much higher Curie temperature than room temperature, along with strong stability in UV light [13]. A visible-ray-active photocatalyst is very important with respect to solar energy and interior lighting applications. For practical application, it has been reported that the enhancement of photocatalytic activity can be achieved by introducing foreign metal ions into $\mathrm{ZnO}$ or creating oxygen vacancies with hydrogen plasma or X-ray irradiation. Thus, many scientists have been studying a method to introduce foreign metal ions, such as $\mathrm{W}^{6+}, \mathrm{V}^{5+}, \mathrm{Cu}^{2+}, \mathrm{Fe}^{3+}$, and into $\mathrm{ZnO}$. In particular, both $\mathrm{Fe}$ - and $\mathrm{Cu}$-doped cases have been widely examined [4-7]. To obtain metal-doped $\mathrm{ZnO}$ powders suitable for their intended applications, the control of particular properties including chemical composition, purity, morphology, and particle size is very important. $\mathrm{ZnO}$ powder has various shapes such as prismatic, ellipsoidal, bipyramidal and dumbbell-like, nanowire, and nanorod by different synthesis method [1]. There are several methods for the synthesis of $\mathrm{ZnO}$ nanopowder, such as sol-gel method, hydrothermal process, gas condensation method, and spray pyrolysis [8-11]. Among them, the hydrolysis synthetic route has the advantage to simply obtain high-crystallized powders. Particularly, cohydrolysis method for preparing metal-doped $\mathrm{ZnO}$ nanorods is simple one-step process. This method is 
easily control crystallization not only of the target materials but also of dopant without any surfactants. The present paper describes the processing details to synthesize $\mathrm{ZnO}$ nanoflower and rods as well as their particulate morphologies such as the phase, size, and shape. We synthesized Fe- and $\mathrm{Cu}$-doped $\mathrm{ZnO}$ nanorods using a simple process employing the hydrolysis of $\mathrm{Zn}, \mathrm{Fe}$, and $\mathrm{Cu}$ nanopowders, which were produced by pulsed wire evaporation (PWE) of metal wire [12]. The present paper describes the processing details for the synthesis of Fe- and $\mathrm{Cu}$-doped $\mathrm{ZnO}$ nanorods as well as the particulate properties of the produced powders such as the phase, size, and photocatalytic effect.

\section{Materials and Methods}

High purity $\mathrm{Zn}, \mathrm{Fe}$, and $\mathrm{Cu}$ nanopowders were synthesized using a pulsed wire evaporation (PWE) method. The Zn, Fe, and $\mathrm{Cu}$ nanopowders have spherical shapes and average sizes of about $80-120 \mathrm{~nm}$, as shown in Figure 1. For a precondition of the hydrolysis reaction, the nanopowders were immersed into distilled water at a regular rate (Fe or $\mathrm{Cu}$ : $0,2,5,8$, $10 \mathrm{wt} . \%)$ and ultrasonically treated for $10 \mathrm{~min}[13,14]$. A small amount of acetic acid was added into the solution, where the acid played a role of promoting the hydrolysis reaction between the nanopowders and $\mathrm{H}_{2} \mathrm{O}$. Hydrolysis has been carried out at $60^{\circ} \mathrm{C}$ for $24 \mathrm{~h}$ to produce the precipitation of both iron and copper doped zinc hydroxide gel. The produced gel was precipitated as $\mathrm{ZnO}$ powders. The precipitated powder has been drawn through filtering using a $0.2 \mu \mathrm{m}$ filter and subsequently dried in an oven at $6^{\circ} \mathrm{C}$ for $12 \mathrm{~h}$. After that, the precipitated powders were heat treated at $300^{\circ} \mathrm{C}$ for $1 \mathrm{~h} \mathrm{[13].} \mathrm{The} \mathrm{particle} \mathrm{size} \mathrm{and} \mathrm{morphology} \mathrm{of} \mathrm{the} \mathrm{particulate}$ samples were examined using a MTE10 transmission electron microscope (TEM) at accelerating voltages up to $300 \mathrm{kV}$. The particles were also analyzed by selected area diffraction.

To investigate the structural properties of the samples produced after the hydrolysis process, an X-ray diffractometer (RIGAKU D/MAX-3C) with $\mathrm{Cu} \mathrm{K} \alpha$ radiation was carried out. The absorption spectra of the samples were recorded using a UV-visible spectrometer. The phenol degrading was measured to evaluate the photocatalytic properties using a solar simulator. The solar simulator consists of $\mathrm{Hg}$-Xe lamp with a wavelength of $200 \sim 2500 \mathrm{~nm}$ and $1 \mathrm{kWatt}$ of power. The photocatalytic activity of the $\mathrm{Fe}$ - and $\mathrm{Cu}$-doped $\mathrm{ZnO}$ nanorod was evaluated according to the photodegradation of phenol aqueous solutions under different irradiation conditions. For experiments under UV-visible light, a $100 \mathrm{~mL} 50 \mathrm{ppm}$ phenol aqueous solution with $0.5 \mathrm{~g}$ sample powders was loaded in a glass container and stirred with a magnetic stirrer a under irradiation of a Hg-Xe lamp. Total organic carbon (TOC) values as a function of time were measured after filtration under reduced pressure $[15,16]$.

\section{Results and Discussion}

3.1. Synthesis of $\mathrm{Fe}$ - and $\mathrm{Cu}$-Doped $\mathrm{ZnO}$. The $\mathrm{ZnO}$ nanoparticles were synthesized by the hydrolysis of nanometal powders. When $\mathrm{Zn}$ metal particles are hydrolyzed with distilled water, the $\mathrm{ZnO}$ phase is formed by the following reaction $[5,13,17]$ :

$$
\mathrm{Zn}+2 \mathrm{H}_{2} \mathrm{O} \longrightarrow \mathrm{Zn}(\mathrm{OH})_{2}+2 \mathrm{H}_{2} \stackrel{\text { precipitation }}{\longrightarrow} \mathrm{ZnO}
$$

After the hydrolysis reaction of the $\mathrm{Zn}$ nanopowder in distilled water, white precipitated materials were obtained and were found to be zinc oxide [13, 14]. Figure 2 shows the transmission electron microscopy (TEM) images for $\mathrm{Fe}$ - and $\mathrm{Cu}$-doped $\mathrm{ZnO}$ nanorods that were synthesized by hydrolysis. The starting material of the produced $\mathrm{Zn}$ nanopowder is spherical with a mean size of $\sim 100 \mathrm{~nm}$. The image shows that the produced $\mathrm{ZnO}$ powder has a rod-like shape with a diameter of $80 \mathrm{~nm}$ and a length of $200 \mathrm{~nm}$, as shown in Figure 2(a). The aspect ratio of the $\mathrm{ZnO}$ nanorod is about 2:5. Figures 2(b) and 2(c) show the images for the $5 \mathrm{wt} . \% \mathrm{Fe}$ - and $\mathrm{Cu}$-doped $\mathrm{ZnO}$ nanorods prepared by hydrolysis. As for the $\mathrm{Fe}$ - and $\mathrm{Cu}$-doped case, a rod shape with a diameter of $40 \mathrm{~nm}$ and a length of $270 \mathrm{~nm}$ is observed, in which the large aspect ratio of the shape is attributable to the hydrolysis of iron and copper.

\subsection{Crystal Structure of Fe- and Cu-Doped ZnO NanoRod.} $\mathrm{Fe}$ - and $\mathrm{Cu}$-doped $\mathrm{ZnO}$ nanorods $(\mathrm{Fe}=0,2,5,8$, and $10 \mathrm{wt} . \%)$ have been synthesized by the hydrolysis of nanometal powders. Characterizations of the crystal structure for the Fedoped $\mathrm{ZnO}$ nanoparticles were carried out at previous studies [13]. Also, characterizations of the crystal structure for the $\mathrm{Cu}$-doped $\mathrm{ZnO}$ nanorods synthesized by the hydrolysis process were carried out by XRD and the results are presented in Figure 3. When the copper powder was cohydrolyzed with zinc in distilled water, $\mathrm{Cu}$-oxides and $\mathrm{Cu}$-hydroxides forms were rarely observed as shown in Figure 3. The copper were well substituted into $\mathrm{Zn}$ sites without changing the crystal structure [18]. The sharp diffraction peaks imply the good crystallization of the samples. The positions and relative intensities of all the main diffraction peaks were in good agreement with those of the standard JCPDS card (JCPDS No. 89-1397, 89-0511, and 89-0510) of ZnO.

Infrared (IR) spectrum is an important measurement, which provides useful information about the structure of a compound. The IR spectrum shape of the $\mathrm{ZnO}$ powder is generally influenced by the particle size and morphology, the degree of a particles aggregation, or the crystal structure of the $\mathrm{ZnO}$ powder [17]. Figure 4 exhibits IR spectra for the pure $\mathrm{ZnO}$ and $\mathrm{Cu}$-doped $\mathrm{ZnO}$ nanopowders. In the IR region, $\mathrm{ZnO}$ usually shows distinct absorption bands around wave numbers of $450 \mathrm{~cm}^{-1}$. Also, this maximum band broadens and often splits into two maxima if the particle morphology changes from a spherical to a needle-like shape, which corresponds well with the two absorption maximum bands observed at around 500 and $400 \mathrm{~cm}^{-1}$ as shown in Figure 3 . The same IR spectra for the Fe-doped $\mathrm{ZnO}$ were observed [13].

3.3. Photocatalytic Characterization of Fe-and $\mathrm{Cu}$-Doped $\mathrm{ZnO}$ NanoRod. In the spectrum of the Fe 2 wt.\%-doped $\mathrm{ZnO}$, it is observed that the absorbance between 400 and $500 \mathrm{~nm}$ 


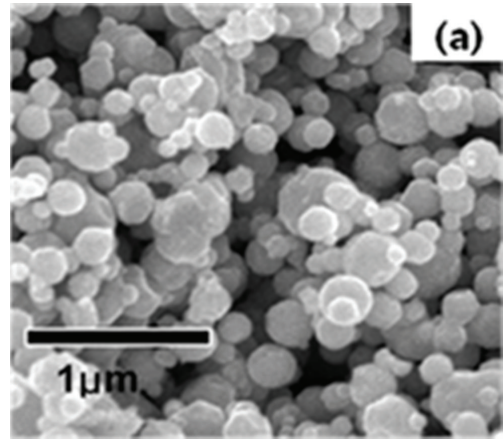

(a)

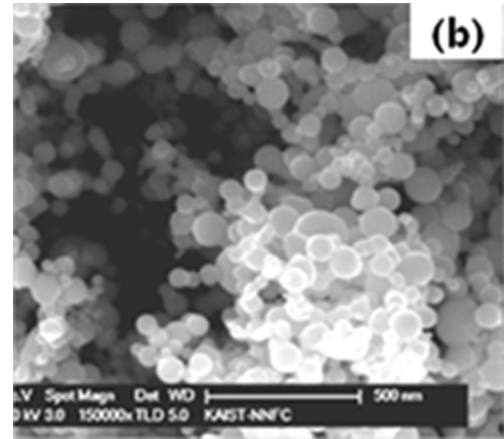

(b)

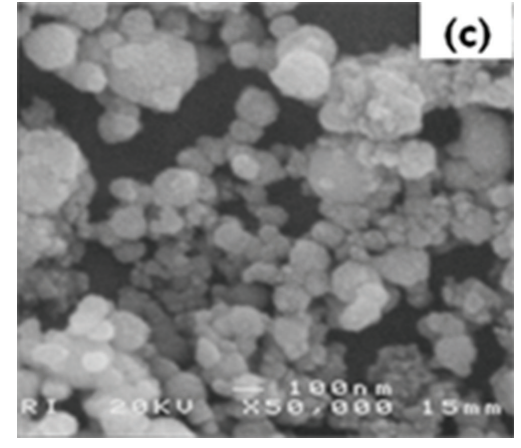

(c)

FIGURE 1: Scanning electron microscope (SEM) images for (a) Zn, (b) Fe, and (c) Cu prepared by pulsed wire evaporation (PWE).

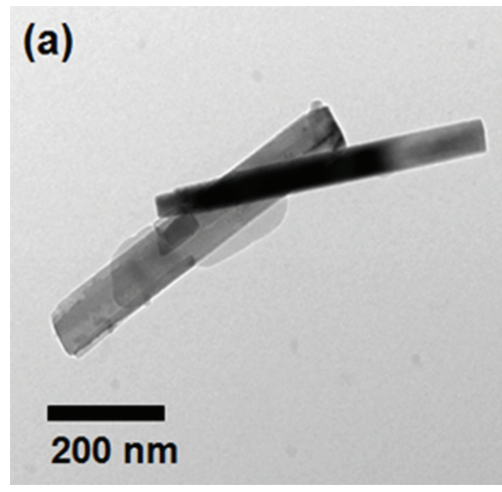

(a)

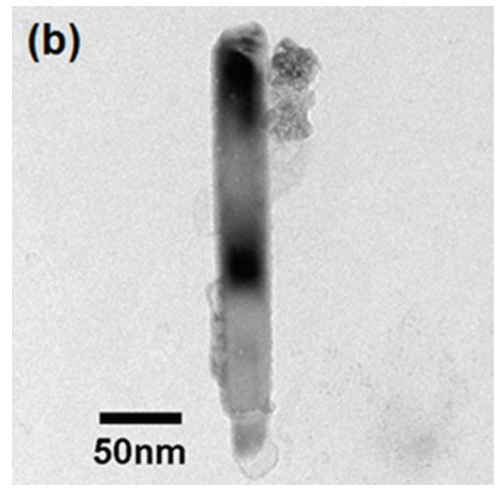

(b)

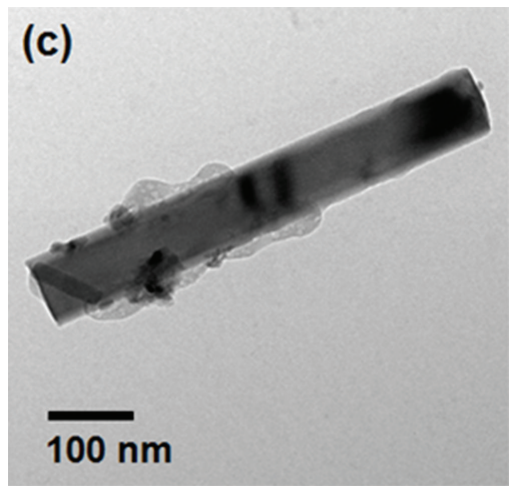

(c)

Figure 2: TEM images for (a) $\mathrm{ZnO}$, (b) 5 wt.\%-Fe-, and (c) 5 wt.\%-Cu-doped $\mathrm{ZnO}$ nanorod.

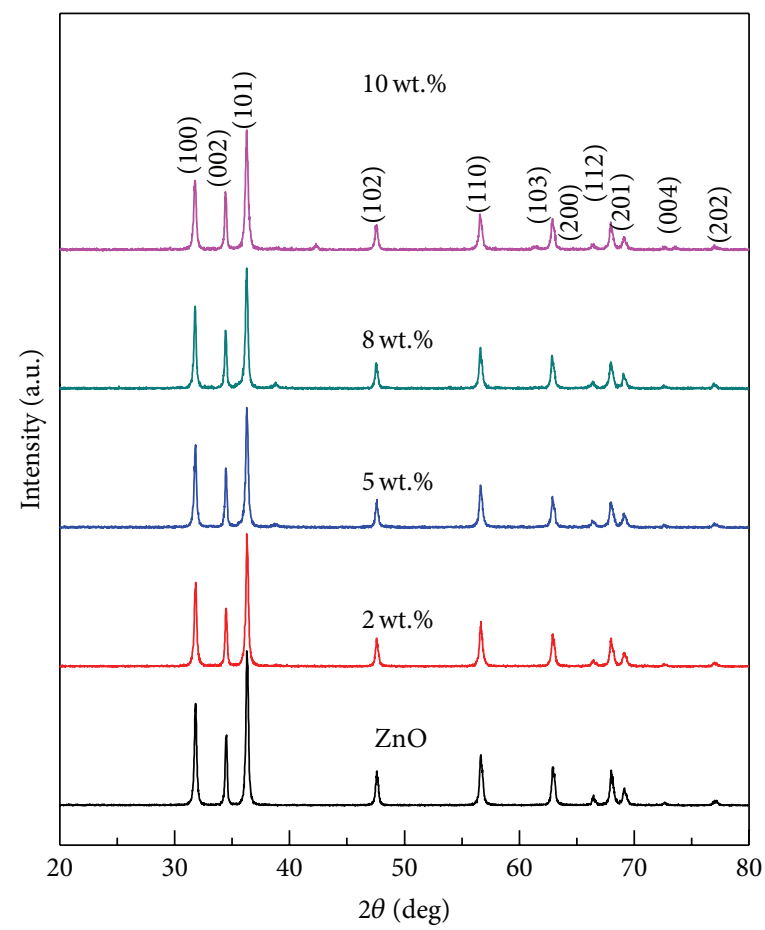

FIGURE 3: X-ray diffraction patterns for the $\mathrm{Cu}$-doped $\mathrm{ZnO}$ nanorods synthesized by the hydrolysis process. (Doping concentration $0,2,5,8$, and $10 \mathrm{wt} . \%$ ). 


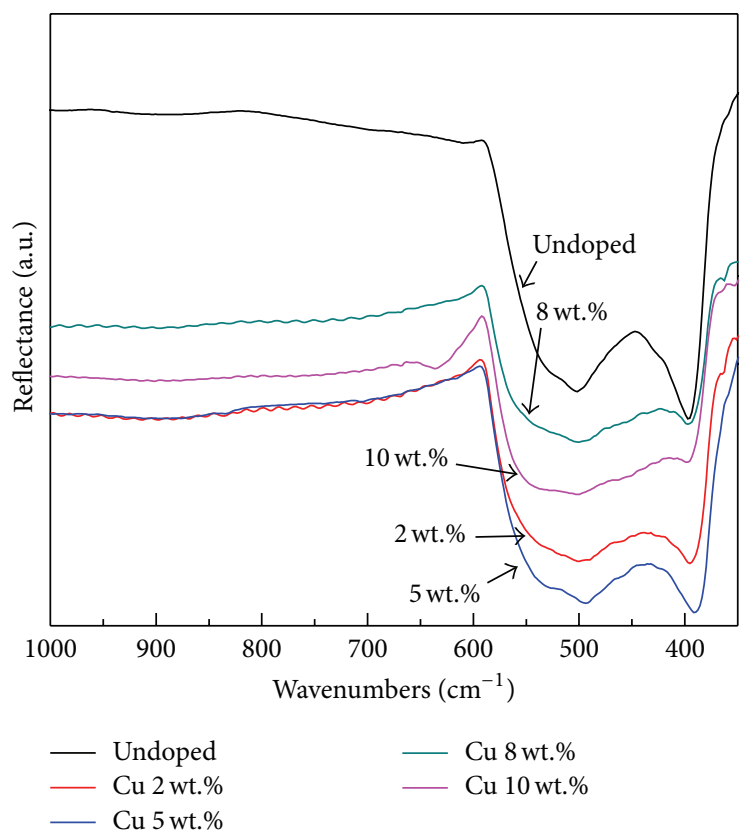

Figure 4: FT-IR spectra of the $\mathrm{Cu}$-doped ZnO nanopowder. Doping concentrations of 0, 2, 5, 8 and 10 wt.\% (Wave number were measured from 200 to $2000 \mathrm{~cm}^{-1}$ ).

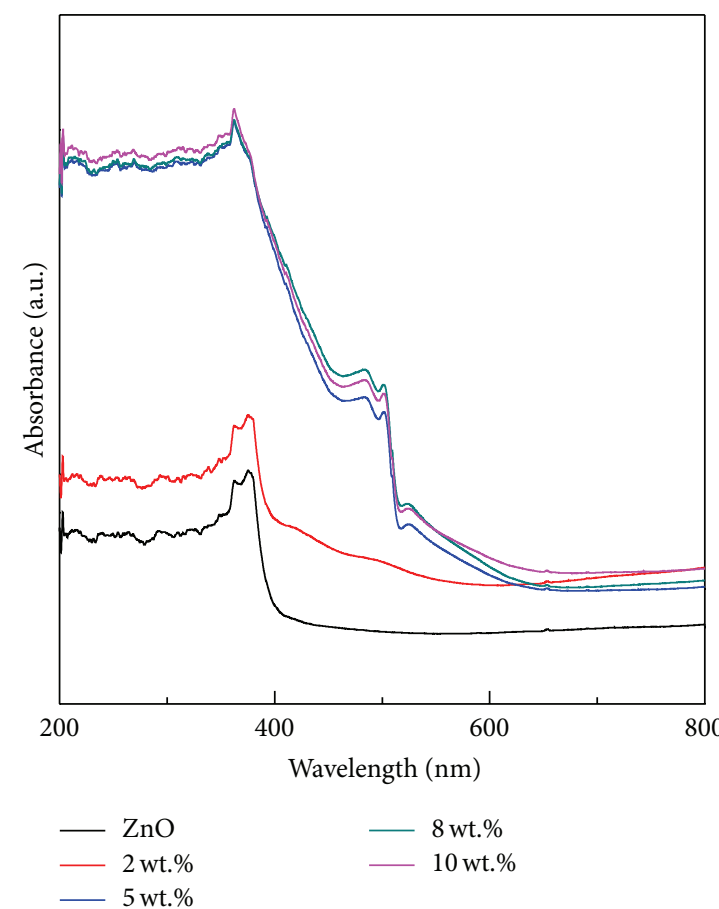

(a)

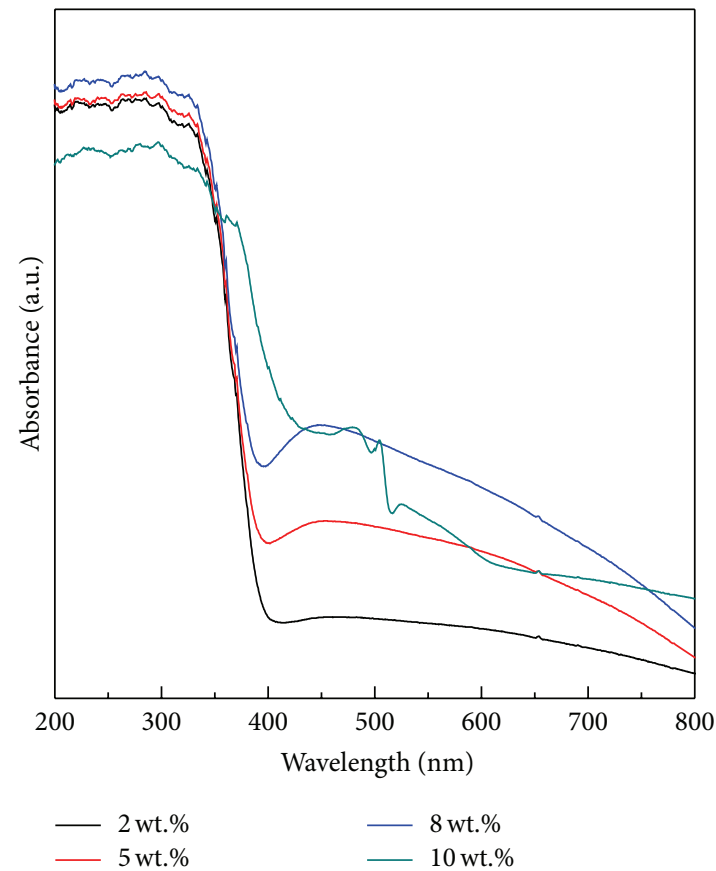

(b)

FIGURE 5: UV-vis absorbance (wavelength from 200 to 800) of the (a) Fe-doped and (b) Cu-doped ZnO nanorods synthesized by hydrolysis process. Doping concentrations of $0,2,5,8$, and $10 \mathrm{wt} . \%$.

begins to increase, when compared with the undoped one [13]. When $\mathrm{ZnO}$ is doped with above $5 \mathrm{wt} . \% \mathrm{Fe}$, the spectra show that the absorption edge shifts to a long wavelength. The introduction of $\mathrm{Fe}$ into $\mathrm{ZnO}$ by substituting the $\mathrm{Zn}$ sites with $\mathrm{Fe}$ ions leads to the appearance of additional absorption bands [13]. These bands are due to the transitions involving crystal field levels in the Fe ions. These transitions are observed in the Fe-doped $\mathrm{ZnO}$ with a doping rate of above 5 wt.\% [13, 14]. Figure 5 shows the UV-vis spectra for the pure and $\mathrm{Cu}$-doped $\mathrm{ZnO}$ nanorods. In the spectrum of 


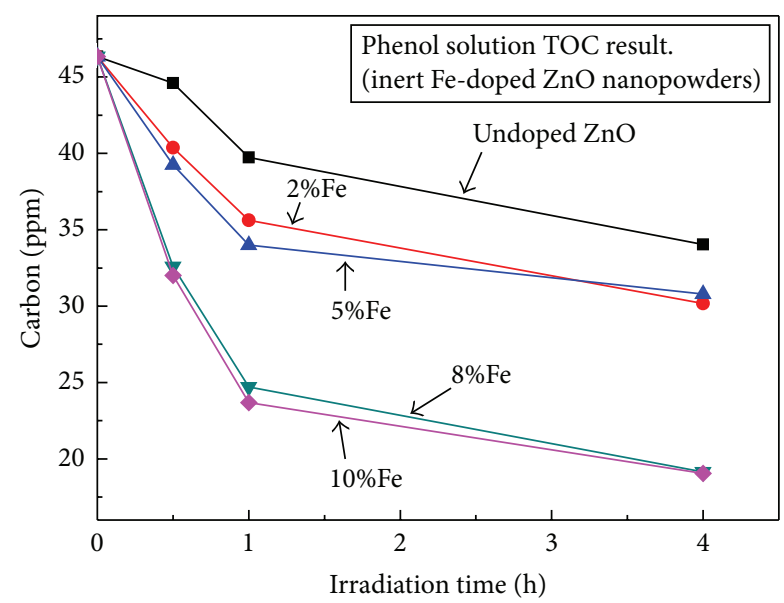

Figure 6: Photomineralization of phenol with sunlight (TOC: total organic carbon content at times) in the presence of Fe-doped $\mathrm{ZnO}$. (Hg-Xe lamp with a wavelength of 200 2500 nm and $1 \mathrm{kWatt}$ of power).

the $\mathrm{Cu} 8$ wt.\%-doped $\mathrm{ZnO}$, it is observed that the absorbance between 400 and $500 \mathrm{~nm}$ begins to increase. When $\mathrm{ZnO}$ is doped with above $10 \mathrm{wt} . \% \mathrm{Cu}$, the spectra show that the absorption edge shifts to a long wavelength. The introduction of $\mathrm{Cu}$ into $\mathrm{ZnO}$ by substituting the $\mathrm{Zn}$ sites with $\mathrm{Cu}$ ions leads to the appearance of additional absorption bands involving crystal field levels in the $\mathrm{Cu}$ ions $[16,17]$. The transitions are observed in a doping rate of above $8 \mathrm{wt} . \%$.

Figure 6 shows the photomineralization of phenol with UV-visible light (solar simulator) in the presence of Fe-doped $\mathrm{ZnO}$. Obviously, Fe-doped $\mathrm{ZnO}$ shows higher activity for a degradation of phenol in an aqueous solution compared to pure $\mathrm{ZnO}$. $\mathrm{ZnO}$ nanorods did not significantly change the total organic carbon value under sunlight irradiation. When $\mathrm{ZnO}$ is doped above $8 \mathrm{wt} . \% \mathrm{Fe}$, the total organic carbon (TOC) value was reduced to $60 \%$.

Figure 7 shows the photocatalytic effect of $\mathrm{Cu}$-doped $\mathrm{ZnO}$ in phenol under UV-visible light (solar simulator). $\mathrm{Cu}$-doped $\mathrm{ZnO}$ shows higher activity for a degradation of phenol in an aqueous solution compared to pure $\mathrm{ZnO}$. The introduction of $\mathrm{Cu}$ into $\mathrm{ZnO}$ by substituting the $\mathrm{Zn}$ sites leads to the additional absorption bands. This additional absorption bands played a role of increasing photocatalytic activity. When $\mathrm{ZnO}$ is doped from 2 to $8 \mathrm{wt} . \%$, the TOC value was reduced to $50 \%$. The largest reducing value of the TOC, $75 \%$, was observed at $10 \mathrm{wt} . \% \mathrm{Cu}$-doped $\mathrm{ZnO}$. This results well correspond to UV-vis spectra. Both Feand $\mathrm{Cu}$-doped $\mathrm{ZnO}$ show higher degradation of phenol in an aqueous solution compared to pure $\mathrm{ZnO}$, because of enhanced absorption threshold of UV-visible light.

\section{Conclusions}

In conclusion, $\mathrm{Fe}$ - and $\mathrm{Cu}$-doped $\mathrm{ZnO}$ nanorods have been synthesized using a simple process employing the hydrolysis of $\mathrm{Zn}, \mathrm{Fe}$, and $\mathrm{Cu}$ nanopowders. TEM result showed that the produced samples had a rod shape. The acetic acid was a key material for the hydrolysis reaction of $\mathrm{Zn}$ metal powder with

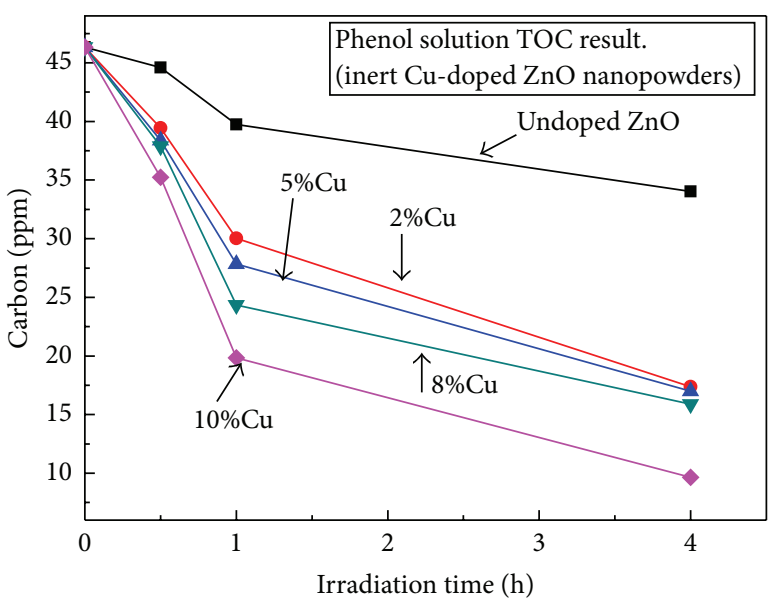

Figure 7: Photomineralization of phenol with sunlight in the presence of $\mathrm{Cu}$-doped $\mathrm{ZnO}$. (Hg-Xe lamp with a wavelength of 200 $2500 \mathrm{~nm}$ and $1 \mathrm{kWatt}$ of power).

a thin oxide surface layer. With increasing doping contents, the UV-vis spectra were shifted to a long wavelength and the substitution of $\mathrm{Cu}^{2+}$ and $\mathrm{Fe}^{3+}$ into $\mathrm{Zn}^{2+}$ led to the appearance of additional absorption bands. Both $\mathrm{Fe}$ - and $\mathrm{Cu}$-doped $\mathrm{ZnO}$ show higher degradation of phenol in an aqueous solution compared to pure $\mathrm{ZnO}$.

\section{Conflict of Interests}

The authors declare no financial conflict of interests.

\section{Acknowledgments}

This research was supported by both "Development of radioisotope production and application technology based on research reactor" funded by Ministry of Science, ICT \& Future planning, and "Development of new processing technology for structural materials of nuclear power plants" funded by Ministry of Trade, Industry \& Energy, in Republic of Korea.

\section{References}

[1] D. C. Look, "Recent advances in $\mathrm{ZnO}$ materials and devices," Materials Science and Engineering B, vol. 80, no. 1-3, pp. 383387, 2001.

[2] X. Wu, Z. Wu, L. Guo et al., "Pressure-induced phase transformation in controlled shape $\mathrm{ZnO}$ nanorods," Solid State Communications, vol. 135, no. 11-12, pp. 780-784, 2005.

[3] Y. Lin, D. Jiang, F. Lin, W. Shi, and X. Ma, "Fe-doped ZnO magnetic semiconductor by mechanical alloying," Journal of Alloys and Compounds, vol. 436, no. 1-2, pp. 30-33, 2007.

[4] M. Quintana, J. Rodríguez, J. Solis, and W. Estrada, “The influence of the ethanol-water molar ratio in the precursor solution on morphology and photocatalytic activity of pyrolytic ZnO films," Photochemistry and Photobiology, vol. 81, no. 4, pp. 783-788, 2005.

[5] Q. A. Pankhurst, J. Connolly, S. K. Jones, and J. Dobson, "Applications of magnetic nanoparticles in biomedicine," Journal of Physics D, vol. 36, no. 13, pp. R167-R181, 2003. 
[6] R. Mohan, K. Krishnamoorthy, and S.-J. Kim, "Enhanced photocatalytic activity of $\mathrm{Cu}$-doped $\mathrm{ZnO}$ nanorods," Solid State Communications, vol. 152, no. 5, pp. 375-380, 2012.

[7] S. Muthaukumaran and R. Gopalakrishanan, "Structural, FTIR and photoluminescence studies of $\mathrm{Cu}$ doped $\mathrm{ZnO}$ nanopowders by co-precipitation method," Optical Materials, vol. 34, pp. 1946-1953, 2012.

[8] C.-H. Lu and C.-H. Yeh, "Influence of hydrothermal conditions on the morphology and particle size of zinc oxide powder," Ceramics International, vol. 26, no. 4, pp. 351-357, 2000.

[9] B.-G. Wang, E.-W. Shi, and W.-Z. Zhong, "Growth habits and mechanism of several polar organic crystals in various solvents II. Molecular packing, interface structures and growth habits," Acta Chimica Sinica, vol. 56, no. 4, pp. 320-327, 1998.

[10] J. Zhang, L. Sun, J. Yin, H. Su, C. Liao, and C. Yan, "Control of $\mathrm{ZnO}$ morphology via a simple solution route," Chemistry of Materials, vol. 14, no. 10, pp. 4172-4177, 2002.

[11] C. Xu, G. Xu, Y. Liu, and G. Wang, "A simple and novel route for the preparation of $\mathrm{ZnO}$ nanorods," Solid State Communications, vol. 122, no. 3-4, pp. 175-179, 2002.

[12] J. H. Park, M. K. Lee, C. K. Rhee, and W. W. Kim, "Control of hydrolytic reaction of aluminum particles for aluminum oxide nanofibers," Materials Science and Engineering A, vol. 375-377, no. 1-2, pp. 1263-1268, 2004.

[13] B. S. Han, Y. R. Uhm, G. M. Kim, and C. K. Rhee, "Novel synthesis of nanorod $\mathrm{ZnO}$ and $\mathrm{Fe}$-Doped $\mathrm{ZnO}$ by the hydrolysis of metal powders," Journal of Nanoscience and Nanotechnology, vol. 7, no. 11, pp. 4158-4160, 2007.

[14] B. S. Han, Y. R. Uhm, and C. K. Rhee, "Synthesis for nanoflower and rod of Zno by a surfactant free and low temperature method," Surface Review and Letters, vol. 17, no. 2, pp. 173-176, 2010.

[15] C. McManamon, J. D. Holmes, and M. A. Morris, "Improved photocatalytic degradation rates of phenol achieved using novel porous $\mathrm{ZrO}_{2}$-doped $\mathrm{TiO}_{2}$ nanoparticulate powders," Journal of Hazardous Materials, vol. 193, pp. 120-127, 2011.

[16] M. Jakani, G. Campet, J. Claverie, D. Fichou, J. Pouliquen, and J. Kossanyi, "Photoelectrochemical properties of zinc oxide doped with 3d elements," Journal of Solid State Chemistry, vol. 56, no. 3, pp. 269-277, 1985.

[17] L. Wu, Y. Wu, Y. Shi, and H. Wei, "Synthesis of $\mathrm{ZnO}$ nanorods and their optical absorption in visible-light region," Rare Metals, vol. 25, no. 1, pp. 68-73, 2006.

[18] D. W. Zeng, C. S. Xie, B. L. Zhu et al., "Controlled growth of $\mathrm{ZnO}$ nanomaterials via doping Sb," Journal of Crystal Growth, vol. 266, no. 4, pp. 511-518, 2004. 

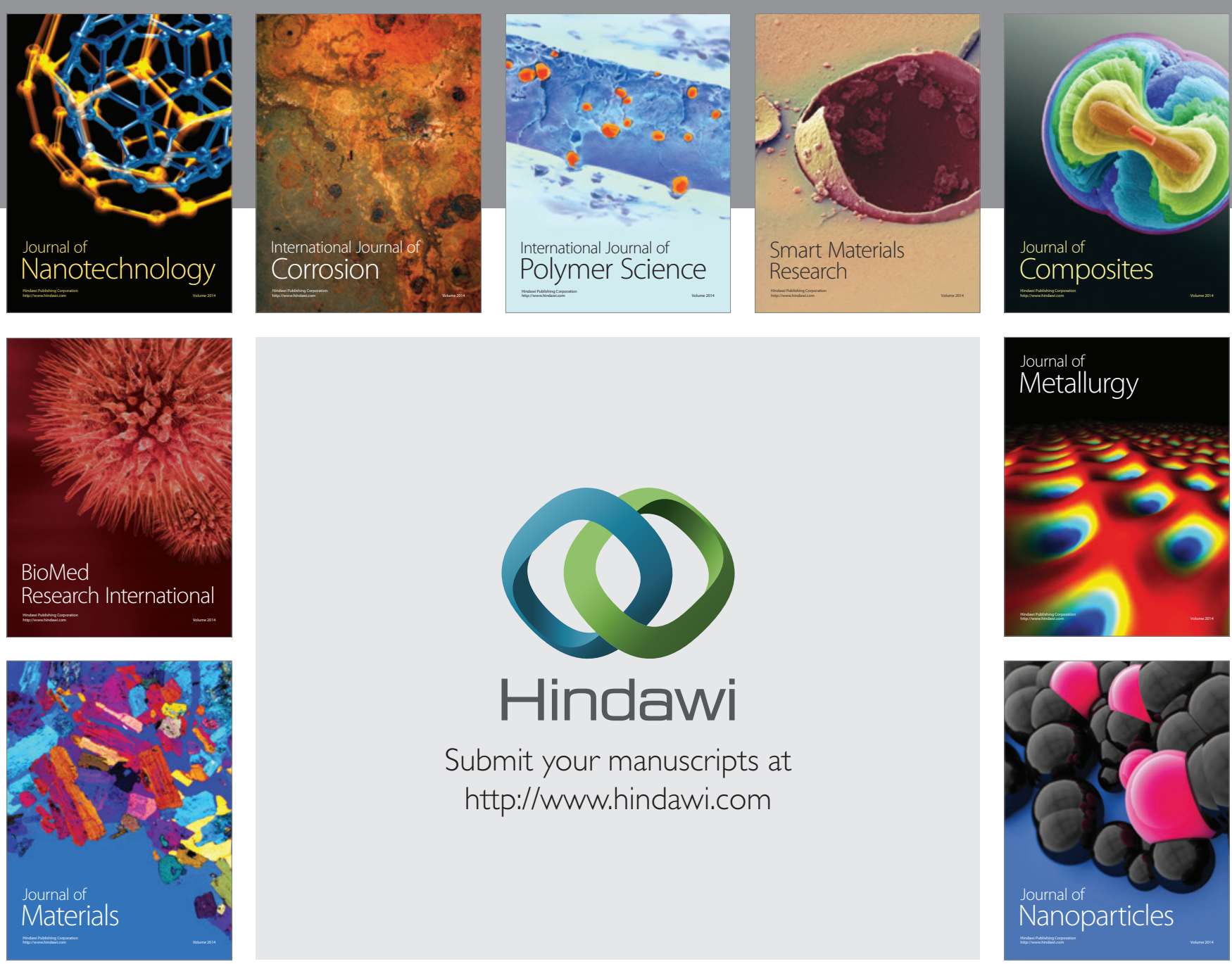

Submit your manuscripts at http://www.hindawi.com
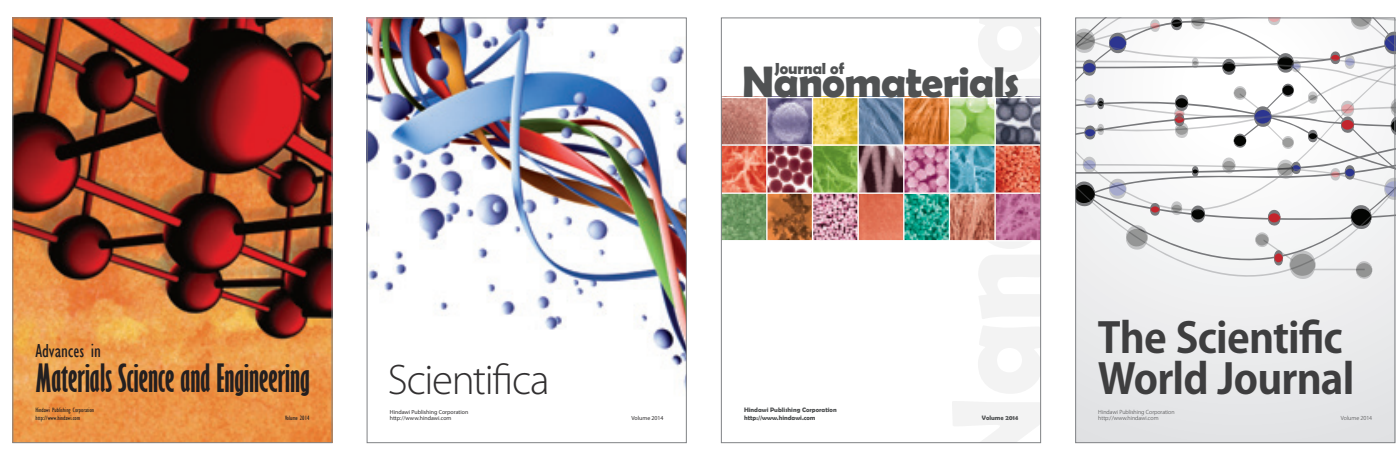

\section{The Scientific World Journal}
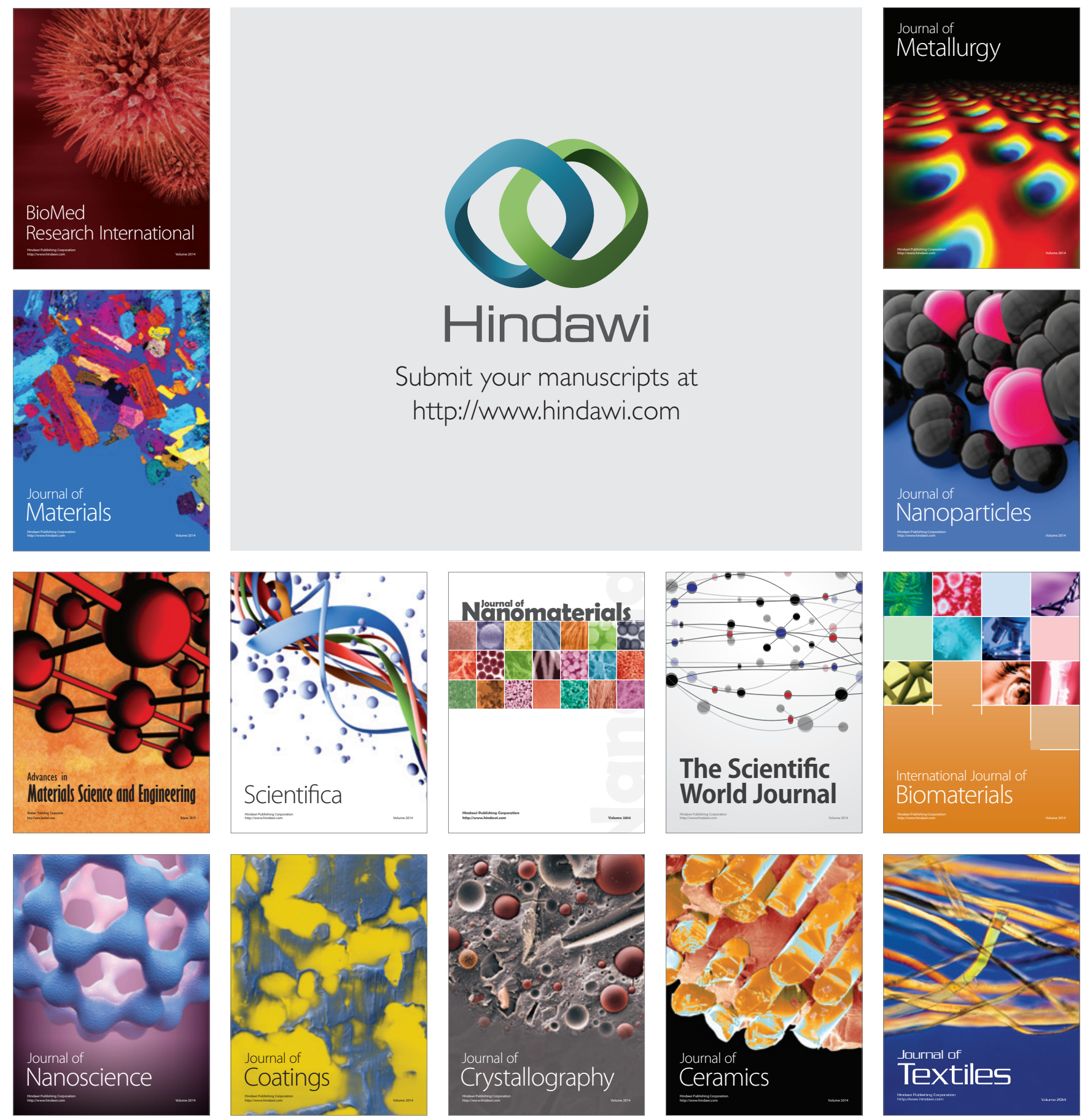